\title{
Avaliação de Diferentes Coberturas na Supressão de Plantas Daninhas no CerRado ${ }^{1}$
}

\author{
Evaluation of Weed Suppression Using Different Crop Covers under Brazilian Cerrado Soil \\ Conditions
}

MESCHEDE, D.K. ${ }^{2}$, FERREIRA, A.B. ${ }^{3}$ e RIBEIRO JR., C.C. ${ }^{3}$

\begin{abstract}
RESUMO - A definição de espécies com elevada produtividade de fitomassa para cobertura do solo é um dos fatores de sucesso do sistema plantio direto. O cultivo de solos tropicais e subtropicais, baseado em práticas de preparo com intenso revolvimento, normalmente resulta na maior incidência de plantas invasoras. Objetivou-se neste trabalho comparar diferentes tipos de cobertura vegetal quanto ao potencial de supressão das plantas invasoras em áreas do cerrado. Foram avaliados sete tipos de cobertura (milheto ADR500, milheto ADR 300, sorgo, milho, crotalária, mamona e vegetação espontânea) mais a testemunha mantida no limpo (capinada). O delineamento foi em blocos casualizados, com quatro repetições. O sorgo apresentou maior peso de cobertura seca $\left(11.890 \mathrm{~kg} \mathrm{ha}^{-1}\right)$ e, juntamente com o milheto e a crotalária, demonstrou maior capacidade de supressão das plantas invasoras, pela maior capacidade de cobertura do solo. A vegetação espontânea apresentou os menores valores de biomassa. O milho e a mamona são culturas com menor potencial de cobertura do solo. O acúmulo de biomassa pelas coberturas foi inversamente proporcional ao da biomassa das plantas invasoras.
\end{abstract}

Palavras-chave: sorgo, milheto, crotalária, mamona.

ABSTRACT - The definition of plant species with higher production for soil mulching is one of the main factors for a successful no-tillage system. The practice of soil tillage in tropical and subtropical regions based on intensive soil revolving results in decreased organic matter and increased weed incidence. Thus, the aim of this work was to compare the potential of different soil mulching to suppress weeds under no-tillage system in Brazilian cerrado areas. Thus, seven treatments were evaluated consisting of the following soil crop covers: Millet ADR 500 (Penisetum americanum $L$.), Millet ADR300, Sorghum (Sorghum bicolor L.), Maize (Zea mays L.), Crotalaria (Crotalaria juncea $L$.), Castorbean plant (Ricinus communis $L$.) and spontaneous vegetation. A randomized block experimental design with 4 replications was used. Sorghum yielded the highest dry matter weight (11.890 kg ha-1); sorghum, millet and crotalaria showed a better ability to suppress weeds. The spontaneous vegetation presented the lowest biomass values. Maize and Castorbean presented a lower crop cover potential. Biomass accumulation by the covers was inversely proportional to weed biomass.

Keywords: sorghum, millet, crotalaria, castorbean.

\footnotetext{
${ }^{1}$ Recebido para a publicação em 22.2.2006 e na forma revisada em 12.2.2007.

${ }^{2}$ Eng ${ }^{\mathrm{Q}}$-Agrônomo, Prof. da Universidade do Estado do Mato Grosso-UNEMAT, Cáceres-MT.

${ }^{3}$ Eng ${ }^{\mathrm{Q}}$-Agrônomo, aluno da Faculdade de Agronomia da UNEMAT.
} 


\section{INTRODUÇÃO}

A grande expansão de áreas de produção agrícola na região do cerrado no Mato Grosso com plantio de soja e algodão tem conduzido à utilização de práticas de manejo do solo intensivas e não adaptadas às condições edafoclimáticas típicas dessas regiões. Em conseqüência, a degradação física, química e biológica desses solos tem aumentado, com reflexo na queda crescente da produtividade, o que gera elevado custo econômico e ambiental. Assim, a adoção de práticas de manejo conservacionista torna-se obrigatória, sendo a manutenção e o incremento no teor de matéria orgânica do solo os principais objetivos.

No sistema plantio direto, a cobertura morta protege o solo da radiação solar, dissipa a energia de impacto das gotas de chuva, reduz a evaporação de água e aumenta a eficiência da ciclagem dos nutrientes (Mateus et al., 2004), além de ser uma alternativa para o controle de plantas daninhas (Vidal \& Bauman, 1996; Oliveira et al., 2001; Severino \& Christoffoleti, 2001). O controle de plantas daninhas pela cobertura vegetal pode ocorrer tanto pelo efeito físico, impedimento da incidência luminosa, como pelos efeitos alelopáticos (Theisen et al., 2000; Fávero et al., 2001).

A cobertura do solo reduz significativamente a intensidade de infestação de plantas daninhas e modifica a composição da população infestante (Mateus, 2004). Solos sem cobertura vegetal apresentam geralmente maior amplitude térmica diária e menor teor de água do que solos protegidos, o que favorece, entre outros, uma maior diversidade de predadores que provocam danos às sementes, diminuindo sua viabilidade e o banco de semente do solo (Vidal \& Theisen, 1999).

As culturas utilizadas como cobertura de solo têm em geral a capacidade de reciclar nutrientes, promover a descompactação do solo, aumentar o teor de matéria orgânica e suprimir as plantas infestantes (Theisen et al., 2000; Trezzi \& Vidal, 2004). A supressão se dá através da produção de metabólitos secundários, denominados aleloquímicos, os quais se acumulam em diversos órgãos das plantas e são liberados no ambiente com uma função ecológica importantíssima. As principais formas de liberação no ambiente ocorrem por meio dos processos de volatilização, exsudação pelas raízes, lixiviação e decomposição dos resíduos (Durigan \& Almeida, 1993).

A ação alelopática, tanto durante o crescimento vegetativo quanto durante o processo de decomposição, exerce inibição interespecífica sobre outras espécies. A inibição está ligada principalmente à reduzida disponibilidade de luz e aos efeitos alelopáticos, que têm potente atividade fitotóxica e podem agir como inibidores do fotossistema II (Czarnota et al., 2003; Kadioglu et al., 2005).

A produção de inibidores bioquímicos, diretamente pelos restos das culturas ou pelos microrganismos do solo, pode inibir a germinação e a emergência de algumas espécies (Matheis, 2004), bem como reduzir o crescimento inicial das plantas.

O uso de cobertura vegetal ajustado às condições edafoclimáticas poderá promover a redução da infestação por plantas daninhas durante o seu desenvolvimento, proporcionando cobertura mais completa ao solo e alteração nas suas características físico-químicas (Skóra Neto, 1993; Severino \& Cristoffoleti, 2001). Assim, o conhecimento desses prováveis efeitos da prática de cobertura permite seu aproveitamento em sistemas de rotação ou consorciação com culturas, no contexto do manejo integrado de plantas daninhas.

Este trabalho teve por objetivo comparar diferentes tipos de cobertura de solo, na supressão das plantas invasoras e manutenção de cobertura morta em áreas do cerrado.

\section{MATERIAL E MÉTODOS}

O experimento foi realizado na Empresa Mato-grossense de Pesquisa e Extensão Rural (EMPAER), no Centro de Pesquisa e Extensão de Cáceres - MT, no período de julho a setembro de 2004 . A latitude do local é de $16^{\circ} 13^{\prime} 42^{\prime \prime}$ e a longitude, de $57^{\circ} 40$ '05".

A área utilizada foi de $2.560 \mathrm{~m}^{2}$, num solo do tipo Podzólico eutrófico. As unidades experimentais foram constituídas de $80 \mathrm{~m}^{2}(10 \mathrm{~m}$ de comprimento por $8 \mathrm{~m}$ de largura) e dispostas em blocos casualizados com oito tratamentos - milheto ADR 500, milheto ADR 300, sorgo 
forrageiro, milho, crotalária, mamona (var. Mirante), testemunha (no limpo, usando enxada) e vegetação espontânea (plantas invasoras) - e quatro repetições.

O preparo do solo foi realizado por operações de gradagem pesada, seguida de gradagem niveladora. A semeadura foi realizada manualmente em sulcos de $5 \mathrm{~cm}$ de profundidade, no espaçamento de 0,5 m entre linhas, respeitando a densidade recomendada para cada espécie. Em razão do manejo adotado para cultura do milho pelos produtores da região, aplicou-se uréia em cobertura, 30 dias após a emergência (DAE).

Para plantio do milheto e da crotalária foram utilizados $12 \mathrm{~kg}$ de sementes por hectare, e para o sorgo, $20 \mathrm{~kg}$. O estande da cultura do milho foi de 50.000 plantas por hectare em sistema adensado, e da mamona, de 40.000 plantas por hectare. Para garantir o estande das culturas, foram realizadas irrigações diárias.

Por ocasião da colheita, aos 90 dias após semeadura, avaliaram-se o número de plantas invasoras (total e por espécie), a composição percentual das espécies daninhas, a luz incidente no dossel, a porcentagem de cobertura do solo e a massa seca total de plantas daninhas e das plantas de cobertura. O levantamento das plantas daninhas (número de plantas por $\mathrm{m}^{2}$ e massa seca) foi feito com o auxílio de um quadrado de $0,5 \times 0,5 \mathrm{~m}$, jogado duas vezes em cada parcela ao acaso. As plantas daninhas foram recolhidas, contadas, separadas por espécies e acondicionadas em sacos de papel, sendo posteriormente levadas para estufa com temperatura média de $70{ }^{\circ} \mathrm{C}$, por 72 horas. Para o levantamento da incidência luminosa, foram amostrados oito pontos distintos em cada parcela, com um luxímetro modelo LD - 22. A amostragem de cobertura do solo foi feita visualmente, por meio de observações de quanto por cento do solo estava coberto pelas plantas.

Os dados foram submetidos à análise de variância e as médias, agrupadas pelo teste de Scott-knott. O pacote estatístico utilizado foi o SAEG.

\section{RESULTADOS E DISCUSSÃO}

Na Tabela 1 são apresentados os valores de massa seca de plantas daninhas e das coberturas. A vegetação espontânea apresentou maior massa seca, diferindo significativamente dos demais tratamentos. A superficie do solo descoberta, além de receber maior quantidade de luz, também tem maior alternância de temperaturas, o que pode estimular a germinação de grande número de espécies. Vidal \& Trezzi (2004) observaram reduções de $41 \%$ de infestação e de $74 \%$ de massa seca total de plantas daninhas comparando as áreas cobertas com culturas à testemunha descoberta.

Theisen et al. (2000), trabalhando com germinação de plantas daninhas em solo desnudo e com cobertura, observaram que solos com cobertura apresentaram menor incidência de B. plantaginea, devido à redução da quantidade e modificação da qualidade da luz que atinge as sementes dessa espécie.

Quando se analisam os demais tipos de cobertura, em relação ao peso de plantas daninhas, com exceção do tratamento de vegetação espontânea, verifica-se que a cobertura com mamona apresentou os maiores valores de massa seca de plantas daninhas. Esses dados revelam como a cultura expõe o solo e favorece a presença das infestantes. Segundo Azevedo et al. (1997), a mamona apresenta crescimento inicial lento, em contraste com algumas espécies daninhas, que chegam a completar seu ciclo produtivo em apenas um mês após a germinação, determinando assim baixa capacidade de cobertura.

A cultura do sorgo mostrou maior massa seca de cobertura em relação aos demais tratamentos, com produtividade média de $11.890,0 \mathrm{~kg} \mathrm{ha}{ }^{-1}$ (Tabela 1). Segu ndo Alvarenga et al. (2001), $6 \mathrm{t} \mathrm{ha}^{-1}$ de matéria seca na superfície é a quantidade suficiente para se obter boa cobertura do solo e, conseqüentemente a manutenção do plantio direto.

Observando a massa da vegetação espontânea e comparando com a massa seca das culturas, é possivel constatar que a área de vegetação espontânea apresentou a menor quantidade de massa seca $\left(2.924,0 \mathrm{~kg} \mathrm{ha}^{-1}\right)$ sendo este um com valor abaixo do 
recomendado para se manter uma boa cobertura do solo.

Na Tabela 2 são apresentados os dados de número de plantas daninhas, incidência luminosa e porcentagem de cobertura do solo. Sorgo, milheto e vegetação espontânea apresentaram melhores porcentagens de cobertura (maior que 90\%). Santos \& Campelo Junior (2003) afirmam que o sorgo (Sorghum bicolor) se adapta a vários ambientes, principalmente sob condições de deficiência hídrica, desfavoráveis à maioria dos outros cereais. Essa característica permite à cultura adaptar-se a áreas adversas e se expandir em regiões de cultivo com distribuição irregular de chuvas e em sucessão a culturas de verão. $\mathrm{O}$ milheto em área de cerrado apresenta boa capacidade de estabelecimento inicial, principalmente por estar adaptado às condições não-favoráveis ao seu desenvolvimento, como a baixa pluviosidade do período (Chaves \& Calegari, 2001). A vegetação espontânea corresponde à espécie de plantas adaptadas, com rápido crescimento inicial, rusticidade e agressividade.

O maior número de plantas daninhas das espécies de cobertura estudadas foi observado na cultura da mamona e do milho, não diferindo significativamente entre si e sendo superior ao das parcelas onde havia vegetação espontânea. Isso ocorreu porque as plantas que germinaram nas parcelas de vegetação espontânea cobriram o solo rapidamente, impedindo que outras espécies germinassem, promovendo uma barreira física para penetração de luz até as sementes que tinham condições de germinação. O maior número de plantas

Tabela 1 - Massa seca de plantas daninhas e plantas de cobertura. Cáceres-MT, 2004

\begin{tabular}{|l|c|c|}
\hline \multicolumn{1}{|c|}{ Tratamento } & Peso de planta daninha $\left(\mathrm{kgha}^{-1}\right)$ & ${\text { Peso de cobertura }\left(\mathrm{kg} \mathrm{ha}^{-1}\right)}$ \\
\hline Milheto ADR 500 & $447,5 \mathrm{D}$ & $5.673,50 \mathrm{C}$ \\
\hline Milheto ADR 300 & $188,5 \mathrm{~B}$ & $7.613,80 \mathrm{C}$ \\
\hline Sorgo forrageiro & $178,5 \mathrm{C}$ & $4.890,00 \mathrm{~A}$ \\
\hline Milho & $500,7 \mathrm{C}$ & $7.541,90 \mathrm{C}$ \\
\hline Crotalária & $274,5 \mathrm{~B}$ & $6.722,75 \mathrm{~B}$ \\
\hline Mamona & $1.001,9 \mathrm{D}$ & $0,00 \mathrm{E}$ \\
\hline Testemunha & $0,0 \mathrm{D}$ & $2.924,00 \mathrm{D}$ \\
\hline Vegetação espontânea & $2.924,0 \mathrm{~A}$ & 18,8 \\
\hline CV $(\%)$ & 18,5 & $\mathrm{cr}$ \\
\hline
\end{tabular}

${ }^{1}$ Médias seguidas de mesma letra maiúscula, em cada coluna, pertencem a um mesmo grupo, de acordo com o critério de agrupamento de Scott-Knott (1974) a 5\% de probabilidade.

Tabela 2 - Número de plantas daninhas, incidência luminosa e porcentagem de cobertura sob os diferentes tipos de cobertura. Cáceres-MT, 2004

\begin{tabular}{|l|c|c|c|}
\hline \multicolumn{1}{|c|}{ Tratamento } & $\begin{array}{c}\text { Número de planta daninha } \\
\left(\mathrm{m}^{2}\right)\end{array}$ & $\begin{array}{c}\text { Incidência luminosa } \\
(\text { Lux })\end{array}$ & $\begin{array}{c}\text { Porcentagem de } \\
\text { cobertura }\end{array}$ \\
\hline Milheto ADR 500 & $6,5 \mathrm{~B}$ & $2050,72 \mathrm{C}$ & $91,25 \mathrm{~A}$ \\
\hline Milheto ADR 300 & $6,8 \mathrm{~B}$ & $3227,93 \mathrm{C}$ & $93,10 \mathrm{~A}$ \\
\hline Sorgo forrageiro & $10,0 \mathrm{~B}$ & $1989,47 \mathrm{C}$ & $96,25 \mathrm{~A}$ \\
\hline Milho & $24,5 \mathrm{~A}$ & $4928,75 \mathrm{~B}$ & $62,50 \mathrm{~B}$ \\
\hline Crotalária & $5,8 \mathrm{~B}$ & $2757,36 \mathrm{C}$ & $95,62 \mathrm{~A}$ \\
\hline Mamona & $25,5 \mathrm{~A}$ & $4811,18 \mathrm{~B}$ & $52,50 \mathrm{C}$ \\
\hline Testemunha & $0,0 \mathrm{~B}$ & $12826,92 \mathrm{~A}$ & $0,00 \mathrm{D}$ \\
\hline Vegetação espontânea & $12,2 \mathrm{~B}$ & $4612,07 \mathrm{~B}$ & $93,75 \mathrm{~A}$ \\
\hline CV $(\%)$ & 54,2 & 25,7 & 5,9 \\
\hline
\end{tabular}

${ }^{1}$ Médias seguidas de mesma letra maiúscula, em cada coluna, pertencem a um mesmo grupo, de acordo com o critério de agrupamento de Scott-Knott (1974) a 5\% de probabilidade. 
daninhas na cultura da mamona também se reflete em menores valores de massa desta na cultura. As menores incidências de plantas daninhas foram observadas nas culturas de milheto, sorgo e crotalária, que não diferiram significativamente entre si. O sorgo e o milheto são plantas $\mathrm{C} 4$, que possuem rápido crescimento e boa capacidade de cobrir o solo. Além disso, o sorgo possui um composto alelopático que é exsudado por suas raízes, o sorgoleone, que é capaz de suprimir diferencialmente o crescimento de várias espécies daninhas e cultivadas (Nimbal et al., 1996). Segundo Calegari (1998), a crotalária leva vantagem em relação a outras culturas porque exige poucas condições de nutrientes dos solos. Sua germinação sobressai em relação à das demais e possui rápido desenvolvimento.

A maior incidência luminosa é verificada no solo descoberto (testemunha - capinada), seguido das culturas de milho e mamona, que não diferiram da vegetação espontânea. Esses dados são compativeis com os observados para número e peso de plantas daninhas, indicando que as culturas de milho e mamona protegem pouco o solo, propriciando o aparecimento das plantas daninhas com maior acúmulo de matéria seca. Esse resultado revela que maiores incidências de luz no solo aumentam significativamente a presença de plantas daninhas e reforça a hipótese de que o efeito físico é o principal supressor no aparecimento das espécies infestantes, permitindo que a cultura consiga expressar melhor seu potencial genético.

A incidência luminosa e a porcentagem de cobertura se apresentaram como ótimas ferramentas para determinar a exposição do solo aos raios solares, havendo correlação inversa entre elas.

Na Tabela 3 são mostradas as espécies de plantas daninhas presentes nos tratamentos, os quais apresentaram composição floristica semelhante, diferindo no aparecimento de algumas espécies e na densidade. Raramente são encontradas, no agroecossistema, plantas isoladas. Elas coexistem com outras plantas, em associações de espécies iguais ou diferentes (Radosevich et al., 1996).

A falsa-serralha esteve presente em todos os tratamentos e em maior quantidade que as outras espécies infestantes. As dicotiledôneas foram as espécies encontradas em maior número; contudo, na cultura de milho e mamona e na vegetação espontânea houve alta incidência de capim-colchão.Como estas

Tabela 3 - Número de espécie por $\mathrm{m}^{2}$ de plantas invasoras presentes em cada cobertura. Cáceres-MT, 2005

\begin{tabular}{|c|c|c|c|c|}
\hline Tratamento & Nome científico da espécie & Família & Nome popular da espécie & Quantidade \\
\hline \multirow{10}{*}{ Milheto ADR 500} & Emilia sonchifolia & Compositae & Falsa- serralha & 8 \\
\hline & Richardia brasiliensis & Rubiaciae & Anjiquinho & 1 \\
\hline & Ipomoea grandifolia & Convolvulaceae & Corda-de-viola & 4 \\
\hline & Commelina benghalensis $\mathrm{L}$. & Commelinaceae & Trapoeraba & 1 \\
\hline & Crotalaria incana $\mathrm{L}$. & Leguminosaceae & Guizo-de-cascavel & 1 \\
\hline & Cleome affinis DC. & Capparaceae & Sojinha & 3 \\
\hline & Bauhinea variegata & Caesalpinioideae & Pata-de-vaca & 2 \\
\hline & Malvastrum coromandelianum & Malvaceae & Guanxuma & 2 \\
\hline & Indigofera hirsuta $\mathrm{L}$. & Leguminosaceae & Anilera & 4 \\
\hline & & & & Total $=$ \\
\hline \multirow{9}{*}{ Milheto ADR 300} & Emilia sonchifolia & Compositae & Falsa-serralha & 4 \\
\hline & Crotalaria incana $\mathrm{L}$. & Leguminosaceae & Guizo-de-cascavel & 1 \\
\hline & Alternantera tenella & Amaranthaceae & Apaga-fogo & 5 \\
\hline & Xanthium strumarium $\mathrm{L}$. & Compositae & Carrapichão & 3 \\
\hline & Digitaria horizontalis & Gramineae & Capim- colchão & 4 \\
\hline & Cleome affinis DC. & Capparaceae & Sojinha & 4 \\
\hline & Indigofera hirsuta $\mathrm{L}$. & Papilionoideae & Anilera & 4 \\
\hline & Ipomoea grandifolia & Convolvulaceae & Corda-de-viola & 2 \\
\hline & & & & Total $=$ \\
\hline
\end{tabular}


Tabela 3, Cont.

\begin{tabular}{|c|c|c|c|c|}
\hline Tratamento & Nome científico da espécie & Família & Nome popular da espécie & Quantidade \\
\hline \multirow{7}{*}{ Sorgo } & Emilia sonchifolia & Compositae & Falsa-serralha & 10 \\
\hline & Phyllanthus corcovadensis & Euphorbiaceae & Quebra-pedra & 1 \\
\hline & Indigofera hirsuta $\mathrm{L}$. & Leguminosae & Anilera & 7 \\
\hline & Cleome affinis DC. & Capparaceae & Sojinha & 8 \\
\hline & Malvastrum coromandelianum & Malvaceae & Guanxuma & 8 \\
\hline & Ipomoea grandifolia & Convolvulaceae & Corda-de-viola & 5 \\
\hline & \multicolumn{4}{|r|}{ Total $=39$} \\
\hline \multirow{10}{*}{ Milho } & Emilia sonchifolia & Compositae & Falsa-serralha & 14 \\
\hline & Phyllanthus corcovadensis & Euphorbiaceae & Quebra-pedra & 2 \\
\hline & Digitaria horizontalis & Gramineae & Capim- colchão & 29 \\
\hline & Indigofera hirsuta $\mathrm{L}$. & Leguminosaceae & Anilera & 18 \\
\hline & Cleome affinis DC. & Capparaceae & Sojinha & 5 \\
\hline & Malvastrum coromandelianum & Malvaceae & Guanxuma & 23 \\
\hline & Ipomoea grandifolia & Convolvulaceae & Corda-de-viola & 2 \\
\hline & Amaranthus deflexus L. & Amaranthaceae & Caruru & 2 \\
\hline & Commelina benghalensis L. & Commelinaceae & Trapoeraba & 2 \\
\hline & \multicolumn{4}{|r|}{ Total $=97$} \\
\hline \multirow{8}{*}{ Crotalária } & Emilia sonchifolia & Compositae & Falsa-serralha & 9 \\
\hline & Digitaria horizontalis & Gramineae & Capim- colchão & 4 \\
\hline & Digitaria horizontalis & Gramineae & Capim-colonião & 2 \\
\hline & Eleusine indica (L.) Gaertn & Gramineae & Pé-de-galinha & 2 \\
\hline & Cleome affinis DC. & Capparaceae & Sojinha & 1 \\
\hline & Malvastrum coromandelianum & Malvaceae & Guanxuma & 3 \\
\hline & Indigofera hirsuta $\mathrm{L}$. & Leguminosaceae & Anilera & 2 \\
\hline & \multicolumn{4}{|r|}{ Total $=23$} \\
\hline \multirow{13}{*}{ Mamona } & Emilia sonchifolia & Compositae & Falsa- serralha & 27 \\
\hline & Digitaria horizontalis & Gramineae & Capim-colchão & 13 \\
\hline & Ipomoea gradifolia & Convolvulaceae & Corda-de-viola & 6 \\
\hline & Amaranthus deflexus L. & amaranthaceae & Caruru & 2 \\
\hline & Commelina benghalensis $\mathrm{L}$. & Commelinaceae & Trapoeraba & 3 \\
\hline & Eleusine indica (L.) Gaertn & Gramineae & Pé-de-galinha & 3 \\
\hline & Senna obtusifolia $\mathrm{L}$. & Caesalpinoideae & Fedegoso & 2 \\
\hline & Aeschynomene denticulata & Leguminosaceae & Angiquinho & 2 \\
\hline & Alternantera tenella & Amaranthaceae & Apaga-fogo & 2 \\
\hline & Malvastrum coromandelianum & Malvaceae & Guanxuma & 14 \\
\hline & Portulaca oleracea L. & Portulacaceae & Beldroega & 2 \\
\hline & Indigofera hirsuta $\mathrm{L}$. & Leguminosaceae & Anilera & 6 \\
\hline & \multicolumn{4}{|r|}{ Total $=82$} \\
\hline \multirow{9}{*}{$\begin{array}{l}\text { Vegetação } \\
\text { espontânea }\end{array}$} & Emilia sonchifolia & Compositae & Falsa-serralha & 16 \\
\hline & Digitaria horizontalis & Gramineae & Capim- colchão & 13 \\
\hline & Ipomoea grandifolia & Convolvulaceae & Corda-de-viola & 8 \\
\hline & Eleusine indica (L.) Gaertn & Gramineae & Pé-de-galinha & 4 \\
\hline & Senna obtusifolia L. & Caesalpinoideae & Fedegoso & 2 \\
\hline & Aeschynomene denticulata & Leguminosaceae & Angiquinho & 2 \\
\hline & Malvastrum coromandelianum & Malvaceae & Guanxuma & 10 \\
\hline & Indigofera hirsuta $\mathrm{L}$. & Leguminosaceae & Anilera & 29 \\
\hline & & & & Total $=85$ \\
\hline
\end{tabular}

coberturas expõem o solo a incidência luminosa (Tabela 2), provavelmente o efeito supressor desta espécie está diretamente ligado ao efeito físico.

Dessa forma, é importante que as espécies mono e dicotiledôneas sejam manejadas utilizando coberturas vegetais que promovam boa cobertura e maior acúmulo de massa seca, no intuito de reduzir a produção de sementes e, conseqüentemente, possibilitar menor emergência de espécies daninhas durante o ciclo das culturas.

Tendo em vista os resultados, é possivel concluir que o sorgo apresentou o melhor 
potencial de produção e quantidade de matéria seca por hectare e a menor produção de massa ficou por conta da vegetação expontânea.

As culturas de sorgo, milheto e crotalária apresentaram boa supressão das plantas invasoras, promovendo maior cobertura do solo e maior captação de luz pelo dossel. A mamona permitiu a maior exposição do solo e maior incidência de plantas daninhas por $\mathrm{m}^{2}$.

Somente a matéria orgânica e o teor de $\mathrm{Mg}$ foram influenciados pelas coberturas. Os menores teores de $\mathrm{Mg}$ foram encontrados nas parcelas que foram mantidas no limpo e com vegetação espontânea, o que pode ter determinado os menores valores de peso seco.

\section{LITERATURA CITADA}

ALTIERI, M. A. et al. A review of insect prevalence in maize (Zea mays L.) and bean (Phaseolus vulgaris L.) polycultural systems. Field Crops Res., v. 1, p. 33-49, 1978.

ALVARENGA, R. C. et al. Plantas de cobertura de solo para sistema plantio direto. Inf. Agropec., v. 22, p. 25-36, 2001.

AZANIA, A. A. P. M. et al. Interferência da palha de canade-açúcar. In: SEVERINO, F. J.; CHRISTOFFOLETI, P. J. Efeitos de quantidades de fitomassa de adubos verdes na supressão de plantas daninhas. Planta Daninha, v. 19, p. $223-228,2001$.

CALEGARI, A. Espécies para cobertura de solo. In: CALEGARI, A. Plantio direto: pequena propriedade sustentável. Londrina: IAPAR, 1998. 255 p. (IAPAR. Circular, 101)

CZARNOTA, N. A.; RIMANDO, A. M. Evaluation of root exudates of seven sorghum accessions. J. Chem. Ecol., v. 29, n. 9, p. 2073-2083, 2003.

DURIGAN, J. C.; ALMEIDA, F. L. S. Noções sobre alelopatia. Jaboticabal: FUNEP, 1993. 28 p.

FAVERO, C. et al. Modificações na população de plantas espontâneas na presença de adubos verdes. Pesq. Agropec. Bras., v. 36, p. 1355-1362, 2001.

GIACOMINI, S. J. et al. Consorciação de plantas de cobertura antecedend o o milho em plantio direto. II Nitrogênio acumulado pelo milho e produtividade de grãos.

R. Bras. Ci. Solo, v. 28, n. 4, p. 1085-1096, 2004.

KADIOGLU, I.; YANAR, Y.; ASAV, U. Allelopathic effects of weeds extracts against seed germination of some plants. J. Environ Biol., v. 26, n. 2, p. 169-173, 2005.
MATHEIS, M. C. A. Efeitos de diferentes coberturas mortas obtidas a partir do manejo mecânico com roçadeira lateral na dinâmica populacional de plantas daninhas em citrus. 2004. 86 f. Dissertação (Mestrado em Fitotecnia) - Escola Superior de Agricultura Luiz de Queiroz, Piracicaba, 2004.

MATEUS, G. P.; CRUSCIOL, C. A. C.; NEGRISOLI, E. Palhada do sorgo de guiné gigante no estabelecimento de plantas daninhas em área de plantio direto. Pesq. Agropec. Bras., v. 39, n. 6, p. 539-542, 2004.

NIMBAL, C. I. et al. Phytotoxicity and distribution of sorgoleone in grain sorghum germplasm. J. Agric. Food Chem., v. 44, n. 5, p. 1343-1347, 1996.

NORMAN, M. J. T.; ROSSIELLO, C. J.; SEARLE, P. G. E. The ecology of tropical food crops . 2.ed. Cambridge: University Press, 1995. 430 p.

OLIVEIRA, M. R. et al. Efeito da palha e da mistura atrazine e metolachlor no controle de plantas daninhas na cultura do milho, em sistema de plantio direto. Pesq. Agropec. Bras., v. 36, p. 37-41, 2001.

RADOSEVICH, S. R.; HOLT, J.; GHERSA, C. Physiological aspects of competition. In: RADOSEVICH, S. R.; HOLT, J.; GHERSA, C. Weed ecology: Implication for managements. New York: John Willey \& Sons, 1996. p. 217 301.

SANTOS, V. S. E.; CAMPELO JÚNIOR, J. H. Influência dos elementos meteorológicos na produção de adubos verdes, em diferentes épocas de semeadura. R. Bras. Eng. Agríc. Amb., v. 7, n. 1, p. 91-98, 2003.

SKORA NETO, F. Controle de plantas daninhas através de coberturas verdes consorciad as com milho. Pesq. Agropec. Bras., v. 28, n. 10, p. 1165-1171, 1993.

THEISEN, G.; VIDAL, R. A.; FLECK, N. G. Redução da infestação de Brachiaria plantaginea em soja pela cobertura do solo com palha de aveia preta. Pesq. Agropec. Bras., v. 35, p. 753-756, 2000.

VIDAL, R. A.; BAUMAN, T. T. Surface wheat (Triticum aestivum) residues, giant foxtail (Setaria faberi), and soybean (Glycine max) yield. Weed Sci., v. 44, n. 5, p. 939943, 1996.

VIDAL, R. A.; TREZZI, M. M. Potencial da utilização de coberturas vegetais de sorgo e milheto na supressão de plantas daninhas em condição de campo: I - plantas em desenvolvimento vegetativo. Planta Daninha, v. 22, n. 2, p. 217-233, 2004.

VIDAL, R. A.; THEISEN, G. Efeito da cobertura do solo sobre a mortalidade de sementes de capim-marmelada em duas profundidades no solo. Planta Daninha, v. 17, p. 339344, 1999. 